\title{
The Intersection of Students' Ideological and Political Education under the Influence of Network Public Opinion
}

\author{
HuangYiling \\ Nanchang Institute of Science \&Technology,Nanchang 330108,China
}

\begin{abstract}
Key words: network public opinion; ideological and political; campus culture; genetic algorithm;
\end{abstract} cross

\begin{abstract}
Under the background of network public opinion, college students' Ideological and political education and campus culture has relevance and cross in the dissemination object and the transmission mode, both of which can be mutually promote each other's development, and provide a strong spiritual impetus to the development of the school. In order to improve the level of College Students' Ideological and political education, a cross mechanism of the students' ideological and political education has been presented based on genetic algorithm, and combined with the modern Internet technology, data mining for the cross of campus culture and the ideological and political education is carried out based on the network public opinion. It is found that there is a strong cross between campus culture and ideological and political education through the analysis, so schools must attach importance to the development of campus culture, while carrying out ideological and political education of college students, so as to improve the level of Ideological and political education by combination of both.
\end{abstract}

\section{Introduction}

Large data network media is one of the main carrier of Ideological and political public opinion on campus, which plays an important role in the expression of student opinion and aspirations, the campus culture is the catalyst for the development process of the ideological and political education of college students. The campus culture and the ideological and political education under the environment of network public opinion has very strong span, focus and direction, which also has complex relevance and cross. So the analysis the cross of influence factors of public opinion information on the campus culture and the ideological and political education, which is helpful to further explore the inherent law of Ideological and political education in the network public opinion information, then we can determine the scope of the ideological and political education of college students, and accurate monitoring of students' Ideological and political behavior, and achieve the intervention of Ideological and political education and teaching.

\section{Intersection of students' ideology and politics and culture under the influence of network public opinion}

Under the influence of network public opinion, the intersection of university student ideological and political and the campus culture is mainly reflected in two aspects, including the dissemination object cross and the dissemination way cross, the following will be described in detail.

(1) The cross of communication objects 
The audiences of Campus culture and the ideological and political education are students, but campus culture also contains the community beyond the campus. The purpose of Ideological and political education of college students is mainly to improve the students' basic ideological and moral quality, students in school is belong to belong to the school, so they need to obey the management of the school. In addition to the needs of the school culture to make students understand the basic knowledge, but also need to promote the community to improve the visibility of the school, improve the competitiveness of the school, so as to promote the development of the school itself. Culture and the ideological and political work are complementary to each other, on the one hand, the campus culture can create a good atmosphere of Ideological and political education for students, on the other hand, overall moral quality of students will improve the school image, there are interaction and mutual influence between the two, especially under the environment of network public opinion.

(2) The cross of transmission mode

The spread of school culture and the ideological and political education can be from the upper transmission to the lower, and can also be fed back to the school from the bottom. the school can improve the whole cultural level, and create a good atmosphere of Ideological and political education through the mutual influences between the school, and also through the social public opinion feedback.

School culture and ideological and political education can cross through the medium, the medium may be school's periodical, and also television media. A good reading publications can be the integration of school culture and ideological and political education together, and exert a subtle influence on the students the good ideological and political education at the same time of the rest and entertainment. School TV station can expand the students' cultural life by playing the advanced deeds, ideological and political outstanding individual selection activities, which can make students' Ideological and political education from the actual life.

Another media that crossing college students ideological and political education and campus culture is the Internet. With the rapid development of Internet technology, especially the open of Wechat, Micro blog, forum and QQ interactive platform, students can acquire mass Ideological and political education information through a variety of communication channels, and the theory of network public opinion appears to be more powerful. Therefore, when ideological and political education is carried out in the school, we must pay attention to network public opinion, and grasp the cross of campus culture and the ideological and political education, which can get better effect.

\section{Cross mechanism of students' Ideological and political education based on genetic algorithm}

In order to study the cross function of network public opinion on College Students' Ideological and political education, the campus culture and ideological and political education is selected as research object in the paper, and the genetic algorithm model is established. Suppose the response function of network public opinion to the ideological and political education is $f(x)$, the number of research object is 4 , and its range is [-1,2], the calculation accuracy is 6 . As the interval length is $2-(-1)=3$, then the closed interval $[-1,2]$ is divided into $3 \times 10^{6}$ equal parts, because $2097152=$ $2^{21}<3 \times 10^{6}<2^{22}=4194304$, the interval needs to be divided into 22 equal parts. A binary string into the range of the corresponding real value is very simple, just two steps, first we need to convert the binary number to decimal value.

$$
\left(b_{21} b_{20} b_{19}, \ldots, b_{1} b_{0}\right)=\left(\sum_{i=0}^{21} b_{i} \cdot 2_{i}\right)_{10}=x^{\prime}
$$


$x^{\prime}$ is corresponds to the real number in interval $[-1,2]$.

$x=-1+x^{\prime} \cdot \frac{2-(-1)}{2^{22}-1}$

Binary string $<0000000000000000000000>$ and $<111111111111111111111>$ represent the boundary value-1 and 2 in the interval respectively, first we randomly generate an initial individuals population of 4 as follows:

$$
\begin{aligned}
& \operatorname{pop}(1)=\{ \\
& <1101110111011001100110> \\
& <1110011011000111110010> \\
& <010110011001010011000> \\
& <010110101101011101001>\}
\end{aligned}
$$

After converting binary data to decimal data, we can get that $\operatorname{pop}(1)=\left\{\begin{array}{lll}1.526125, & 0.545369, & -0.728562,0.321568\end{array}\right\}$

Then the adaptive function is defined as formula (3),

$$
g(x)\left\{\begin{array}{cl}
f(x)-F_{\min }, & \text { if } f(x)-F_{\text {min }}>0 \\
0, & \text { others }
\end{array}\right.
$$

In the formula (3), $F_{\min }$ can not only be a specified value, but also be minimum value in $f(x)$ from the current genetic all generation, here the specified value is selected to facilitate the calculation, hypothesis $F_{\min }=-1$, so when $f(x)=1$, the adaptive function $g(x)=2$, when $f(x)=-1.1$, the adaptive function $g(x)=0$, then we can get the value of objective function.

By the initial population generated above, we can calculate the value of the objective function as follows

$f[\operatorname{pop}(1)]=\{1.256545,1.321566,-1.256515,0.956235\}$

The objective function is re-valued by using the adaptive function, take $F_{\min }=-1$

$g[\operatorname{pop}(1)]=\{2.256545,2.321566,0,1.956235\}$

For a given size of $n$ group pop $=\left\{a_{1}, a_{2}, a_{3}, \ldots, a_{n}\right\}$, the fitness of individual $a_{i}$ is $g\left(a_{i}\right)$, then the probability that the individual is selected is shown in formula (4).

$$
P_{s}\left(a_{i}\right)=\frac{g\left(a_{i}\right)}{\sum_{i=1}^{n} g\left(a_{i}\right)} \quad, i=1,2,3, \ldots, n
$$

The given population is selected by probability, the minimum probability is eliminated through the probability calculation, then the maximum probability is added to the vacant position, the new species are got as follows:

$$
\begin{aligned}
& \text { newpop }(1)=\{ \\
& <1101110111011001100110> \\
& <1110011011000111110010> \\
& <1110011011000111110010> \\
& <010110101101011101001>\}
\end{aligned}
$$

Crossover operation is to exchange a gene of initial chromosome, then a new chromosome can be got, The front six binary in the first group of chromosomes data of and six binary code behind in the second group of chromosomes data is crossed by the crossover operation in the paper, the new chromosome group are as follows:

jchpop $(1)=\{$

$<1101110111011001100110>$ 
$<1001101011000111110111>$

$<1110011011000111110010>$

$<110010101101011111001>$ \}

A gene on the chromosome will be changed by mutation operator, the seventh genes in the first group of chromosomes will be mutated by this operation, the new chromosome is obtained as follows

$\operatorname{pop}(2)=\{$

$<1101111111011001100110>$

$<1001101011000111110111>$

$<1110011011000111110010>$

$<110010101101011111001>$ \}

And then the above selection, crossover and mutation can be repeated until meeting the termination conditions. We can get the cross feature of the campus culture and ideological and political education through the data screening.

\section{Study on the cross feature of students Ideological and political education based on Internet public opinion}

The questionnaire survey is used in this research, questionnaire is issued by the Internet, cloud and mobile client, issuing platform including QQ group, Wechat groups, forums and Weibo, survey project is mainly cross feature of campus culture and the ideological and political education.

Tab. 1 The questionnaire reliability test results

\begin{tabular}{|l|c|c|}
\hline \multicolumn{1}{|c|}{ variable } & CR & AVE \\
\hline Campus culture A1 & 0.826 & 0.782 \\
\hline Ideological and political education A2 & 0.895 & 0.756 \\
\hline
\end{tabular}

Table 1 shows the measured results of the questionnaire survey, from the table we can see that the CR and AVE values are above 0.7, and reliability coefficients were higher, indicating that the questionnaire has good reliability. The genetic algorithm is used to the cross feature data mining, and the results is obtained that is shown the table 2.

Tab. 2 The data cross characteristics

\begin{tabular}{|c|c|c|c|}
\hline factor & item & A1 & A2 \\
\hline \multirow{3}{*}{ A1 } & correlation coefficient & 1.000 & $0.835^{* *}$ \\
\cline { 2 - 4 } & Sig. (bilateral) & .001 & .030 \\
\cline { 2 - 4 } & $\mathrm{N}$ & 600 & 600 \\
\hline \multirow{3}{*}{ A2 } & correlation coefficient & $0.518^{* *}$ & $0.630^{* *}$ \\
\cline { 2 - 4 } & Sig. (bilateral) & .012 & .023 \\
\cline { 2 - 4 } & $\mathrm{N}$ & 600 & 600 \\
\hline
\end{tabular}

Table 2 represents data cross characteristics by genetic algorithm for mining the data, and the data sample is 600 . By the data in the table, we can see that the higher degree of intersection of campus culture and the ideological and political education data.

\section{Conclusion}

With the continuous development of Internet technology, the ideological and political education work in Colleges and universities are faced with great challenges under the background globalization of information makes, many colleges and universities are looking for the right way of 
education reform. This study is based on the monitoring data of network public opinion, the campus culture and the ideological and political education work are effectively combined, and the cross correlation and cross between them is analyzed by using genetic crossover algorithm. The ideological and political education of college students and the modern Internet technology can be combined, only in the way of establishment a perfect ideological and political monitoring mechanism of public opinion network, which can improve the efficiency and level of the teaching of Ideological and political education in Colleges and universities.

\section{Acknowledgement}

The work was supported by the 2014 annual project of the Party Construction in Universities of Jiangxi Province with the project number JXGXDJKT.QN-201469.

\section{Reference}

[1] Chen Yijin, Cao Shujin, Chen Guihong. Opinion mining of network public opinion: Research on the emotional tendency analysis of users comments[J]. Document, information \& Knowledge, 2013 (6): $90-96$

[2] Wang Lancheng, Xu Zhen. Analysis of the thematic network public opinion tendency based on Emotion Ontology [J]. Information and Control, 2013 (1): 46-52

[3] He Tian Xiang, Zhang Hui, Li Bo, etc.. A sentiment analysis of online public opinion based evolution analysis method [J]. Software Guide 2015 (5): 131-134.

[4] Zhang Xiaoxia, Wang Mingyang, He Huixin. Key nodes mining of public opinion network based on sentiment analysis (J). Journal of Xinjiang University (Natural Science Edition), 2015(2): $1-6$

[5] Cao Xueyan, Duan Feifei, Fang Kuan, etc.. Network forum, from the perspective of identifying the key node of unexpected events of public opinion and classification [J]. Library and information Service, 2014, 58 (4): 65-70.

[6] Huang Weidong, Chen Lingyun, Wu Meirong. Study on the emotional evolution of online public opinion topic [J]. Journal of Intelligence, 2014 (1): 102-107

[7] Wang Junxiu. Social psychology: a study of social psychology in Transitional Society [J]. Sociological Studies, 2014 (1): 104-124,244

[8] Chen Shizhan, Feng Zhiyong. Service network: a new base for service composition [J]. Application Research of Computer, 2008, 25 (5): 1378-1382.

[9] Zhang Dalu, Lv Tao. Web service semantic concept annotation based on frequency [J]. Journal of Tongji University (Natural Science Edition), 2008, 36 (1): 103-107. 